\title{
(2) OPEN ACCESS \\ Quantile regression of tobacco tax pass-through in the UK 2013-2019. How have manufacturers passed through tax changes for different tobacco products?
}

\author{
Luke Brian Wilson $\odot,{ }^{1}$ Robert Pryce, ${ }^{1}$ Rosemary Hiscock $\odot,{ }^{2}$ Colin Angus, ${ }^{1}$ \\ Alan Brennan, ${ }^{1}$ Duncan Gillespie ${ }^{1}$
}

${ }^{1}$ School of Health and Related Research, University of Sheffield, Sheffield, UK

${ }^{2}$ Tobacco Control Research Group, University of Bath, Bath, UK

Correspondence to Luke Brian Wilson, School of Health and Related Research, University of Sheffield, Sheffield, UK; I.b.wilson@sheffield.ac.uk

Received 15 May 2020 Revised 1 September 2020 Accepted 7 September 2020
Check for updates

(c) Author(s) (or their employer(s)) 2020. Re-use permitted under CC BY. Published by BMJ.

To cite: Wilson $L B$, Pryce $R$, Hiscock R, et al. Tob Control Epub ahead of print: [please include Day Month Year]. doi:10.1136/

tobaccocontrol-2020-055931

\section{ABSTRACT}

Background The effectiveness of tax increases relies heavily on the tobacco industry passing on such increases to smokers (also referred to as 'pass-through'). Previous research has found heterogeneous levels of tax pass-through across the market segments of tobacco products available to smokers. This study uses retail sales data to assess the extent to which recent tax changes have been passed on to smokers and whether this varies across the price distribution.

Methods We use panel data quantile regression analysis on Nielsen commercial data of tobacco price and sales in the UK from January 2013 to March 2019 combined with official UK tax rates and inflation to calculate the rate of tax pass-through for factory made (FM) cigarettes and roll your own (RYO) tobacco.

Results Following increases in the specific tax payable on tobacco, we find evidence of overshifting across the price distribution for both FM and RYO. The rate of the overshift in tax increased the more expensive the products were. This was consistent for FM and RYO. Additionally, our findings suggest that the introduction of standardised packaging was not followed by changes in how the tobacco industry responded to tax increases. Conclusions Following the repeated introduction of increases in specific tobacco tax as well as standardised packaging, we show that the tobacco industry applies techniques to keep the cheapest tobacco cheaper relative to the more expensive products when passing on tax increases to smokers.

\section{INTRODUCTION}

In the UK, the tax structure applied to tobacco products includes three types of tax (excluding heated tobacco products). First, a specific tax, this is a fixed amount per 1000 factory made (FM) cigarettes or per $1000 \mathrm{~g}$ of roll your own (RYO) tobacco. These lump-sum rates are different between FM and RYO. Second, a tobacco ad valorem tax, that is only applied to FM cigarettes, which is a proportion of the retail price $(16.5 \%$ of the recommended retail price, RRP). This tax rate was set in March 2011 and has not changed in the time frame of this study. The ad valorem tax is only applied to FM cigarettes in the UK. Finally, there is a general value-added tax (VAT), which is a UK sales tax that is applied to most goods and services. Throughout the period of analysis, the rate of VAT has remained unchanged at $20 \%$ value-added on top of the retail price. Table 1 shows two examples of RRPs for FM and
RYO broken down into the various tax elements payable on each product as of October 2018.

In May 2017, the UK introduced a minimum excise tax (MET) on FM cigarettes. The MET, in effect, sets a price floor for the added total of two of the components (specific and tobacco ad valorem, but not VAT) charged to each product. If the total amount of specific and ad valorem tax payable on each product falls below the MET, then the tax payable is that of the MET rather than the sum of the specific and ad valorem tax elements.

A substantial body of evidence has documented the effectiveness of tobacco tax increases on reducing tobacco prevalence, ${ }^{1-5}$ participation ${ }^{6-9}$ and initiation ${ }^{10-12}$ as well as raising government revenue. However, the effectiveness of tax increases on health-related outcomes relies heavily on the tobacco industry (TI) passing on such tax increases to smokers, also known as tax pass-through. ${ }^{13-15}$ Previous work revealed that, between 2000 and 2015 in the UK, the TI passed on tax increases to smokers differently depending on the market segment of the product. They did this by absorbing tax increases on the cheapest products in the price distribution (undershifting), while simultaneously increasing the price, above the tax increase, of the relatively more expensive products (overshifting) in order to try and maximise revenue or maintain profits. ${ }^{13} 16$ Research conducted for the period before standardised packaging in the UK found that the TI uses a variety of strategies to keep the cheapest FM cigarettes and RYO tobacco cheap. This includes the use of price-marked packaging, smaller pack sizes as well as dropping net revenue per pack by 18 pence per pack at the time of a UK budget, absorbing the tax increase and accentuating the price gap between premium and ultra-low price products. ${ }^{1316}$

When examining the claims made by the TI that tax increases will only increase the demand for illicit tobacco, further research in the UK found that the TI increased its prices beyond that required by tax changes, even when tax changes were larger or unexpected, thus increasing revenue for all products except for FM sub value 19 stick. ${ }^{14}$ On all but the cheapest brands, the authors found that these proportions were approximately 55\% (industry price increase) and $45 \%$ (tax). ${ }^{17}$

The UK government additionally introduced standardised packaging for all FM and RYO tobacco. ${ }^{18}$ This required the removal of colourful expression of brands as well as the standardisation of other key 
Table 1 Breakdown of taxes applied to factory made cigarettes and roll your own tobacco

\begin{tabular}{lcccc}
\hline & \multicolumn{2}{l}{$\begin{array}{l}\text { Factory made (FM) } \\
\text { cigarettes } \\
\text { 20 sticks (f) }\end{array}$} & \multicolumn{2}{l}{$\begin{array}{l}\text { Roll your own (RYO) } \\
\text { tobacco } \\
30 \mathrm{~g}(\mathrm{f})\end{array}$} \\
\hline & 8.50 & 12.00 & 14.50 & 15.19 \\
\hline Price (RRP) & 1.42 & 2.00 & 2.42 & 2.53 \\
\hline VAT at standard rate (20\%) & 1.40 & 1.98 & & \\
\hline $\begin{array}{l}\text { Ad valorem tax (at 16.5\%) } \\
\text { Specific tax for 1000 }\end{array}$ & 228.29 & 228.29 & 234.65 & 234.65 \\
cigarettes/g & 4.57 & 4.57 & 7.04 & 7.04 \\
$\begin{array}{l}\text { Specific tax for 20 } \\
\text { cigarettes/30 g }\end{array}$ & 7.39 & 8.55 & 9.46 & 9.57 \\
\hline Total tax & 87 & 71 & 65 & 63 \\
\hline Tax (\% of RRP) & 1.11 & 3.45 & 5.04 & 5.62 \\
\hline Net revenue & & & & \\
\hline
\end{tabular}

The specific tax for 1000 cigarettes $/ \mathrm{g}$, ad valorem, and VAT rates as of October 2018.

RRP, recommended retail price; VAT, value-added tax.

features of the packaging such as the dark brown colour packaging (Pantone 448C), font, health warnings and imagery and pack size (minimum 20 -stick for FM and $30 \mathrm{~g}$ for RYO). This came partially into force on 20 May 2016, in which all newly manufactured or imported FM or RYO products had to comply with the standardised packaging. To allow for the sale of existing stock, full implementation, in which all products had to comply with standardised packaging, came into force on 20 May 2017. Therefore, the appearance of standardised packs in our period of analysis occurs gradually.

Contrary to the initial arguments made by the TI, researchers found that there was no long-term lowering of tobacco prices following the introduction of standardised packaging and MET. ${ }^{15} 19$ They found that tax changes following the implementation of these policies were more widely and quickly passed on to smokers in the form of higher prices for FM and RYO. However, sales volumes of RYO continued to increase throughout the study period, perhaps because RYO remains a less expensive means of smoking tobacco.

This study aims to use market research sales data at stock keeping unit (SKU) level to investigate the extent to which tobacco tax changes are passed through to smokers in the UK. Our period of study is January 2013 to March 2019, which covers a longer period both prestandardised and poststandardised packaging than previous work. ${ }^{15}$ We adjust for inflation over the period, and compute expected counterfactual prices if all tax changes had been passed through to smokers exactly. The statistical analysis extends previous work by applying panel data quantile regression methods to the monthly pricing data in order to produce estimates of undershifting or overshifting of the tax changes at different price points covering the cheapest to most expensive products. We examine the extent of tax pass-through over the full period and compare differences prestandardised and poststandardised packaging introduction. As of 2020, 14 countries have implemented standardised packaging and four more have passed legislation, so our results are globally relevant.

\section{METHODS}

\section{Nielsen Scantrak data}

We used monthly UK data from Nielsen Scantrak from January 2013 to March 2019. Nielsen is a global measurement and data analytics company that provides data on the tobacco markets worldwide. Scantrak data are collected at the point of sale in which an electronic barcode of FM cigarettes or RYO tobacco is scanned via electronic point of sale system during a purchase at a participating retailer. Nielsen collect sales data from $87 \%$ of Great Britain's supermarkets, $15 \%$ of its convenience stores (including 83\% of supermarket-owned convenience stores, 59\% of petrol station forecourts, $6 \%$ of convenience store chains and $4 \%$ of independent retailers) and $17 \%$ of Northern Irish stores with grocery sales (Northern Ireland represents $2.8 \%$ of the UK population). The sampling includes $100 \%$ of the big four UK supermarkets (Tesco, Sainsbury, Asda and Morrisons). For other stores, stratified random sampling with replacement is used. Nielsen then models this Scantrak data to provide a data set that is representative of the UK as a whole using expansion factors based on the region, shop type and shop company. ${ }^{20}$

Nielsen provided the research team with a data set in which each row is a specific SKU in a specific month. Nielsen calculates the price paid per pack for each SKU as well as the volume of sales (number of sticks sold for each SKU). Following on from the previous literature, ${ }^{13} 21-23$ we focus on a four-level product hierarchy within the TI: brand (eg, John Player), brand family (eg, John Player Special), brand variant (eg, John Player Special Real Blue), and the lowest available indicator, SKU (eg, John Player Special Real Blue King Size x20).

As well as providing identifiers used in the four-level product hierarchy, for each SKU, Nielsen provides the number of sticks sold per pack for FM and the grams per pack for RYO, whether the SKU is 'price-marked' or whether the SKU has standardised packaging. For sample design reasons, Nielsen recommended only analysing SKUs that have a market share greater than $0.8 \%$. This also follows previous literature that has used similar data. ${ }^{13-15}$

FM products were classified as being in either 'fully branded packaging' which is the old-style colourful packaging sold in a variety of stick sizes, or standardised packaging ${ }^{19}$ which was introduced in the UK between May 2016 and May 2017. Branded packaging could further be either price-marked (price printed on the packaging) or non-price-marked. The Nielsen data do not specify whether RYO was in branded or standardised packaging, therefore we classified RYO tobacco as standardised packaging if it was $30 \mathrm{~g}$ and appeared in the data post the introduction of standardised packaging.

\section{The counterfactual expected price}

For every SKU in our analytic sample, we constructed a monthly time series of the counterfactual expected price based on the 'baseline' actual price at the time point when the product is first observed in the Nielsen data, and the expected impact of both inflation and tax changes in subsequent months, assuming all tax increases had been fully passed through to the smoker. table 2 summarises all the specific tax changes that have occurred between 2013 and 2019. We then compare this to the actual observed prices at which that product was sold in subsequent months.

One of the key variables of interest in our study is the expected price per stick E[Price]. This is the price per stick in pence for each SKU $i$ assuming that there is full tax passthrough at the time of the specific tax change $t$. In order to calculate the expected price per stick, we first calculated the net revenue from each pack; this was done by removing all tobacco taxes applied to that product at a point in time.

The tax applied to each SKU varies depending on whether they are FM cigarettes or RYO tobacco. The tax duty on FM cigarettes consists of three elements: a specific component 
Table 2 Tobacco-related tax changes during the period of analysis

\begin{tabular}{|c|c|c|c|c|c|c|c|c|c|}
\hline Tax & March 2012 & March 2013 & March 2014 & March 2015 & March 2016 & March 2017 & May 2017 & $\begin{array}{l}\text { November } \\
2017\end{array}$ & $\begin{array}{l}\text { October } \\
2018\end{array}$ \\
\hline \multicolumn{10}{|c|}{ Panel A: Specific excise tax for each tobacco type over time } \\
\hline Factory made* & 167.41 & 176.22 & 184.10 & 189.49 & 196.42 & 207.99 & 207.99 & 217.23 & 228.29 \\
\hline Minimum excise tax & & & & & & & 268.63 & 280.15 & 293.95 \\
\hline Roll your own‡ & 164.11 & 172.74 & 180.46 & 185.74 & 198.10 & 209.77 & 209.77 & 221.18 & 234.65 \\
\hline \multicolumn{10}{|c|}{ Panel B: Change in specific excise tax from previous period } \\
\hline Factory made & & 8.81 & 7.88 & 5.39 & 6.39 & 11.57 & 0.00 & 9.24 & 11.06 \\
\hline Roll your own & & 8.83 & 7.72 & 5.28 & 12.36 & 11.67 & 0.00 & 11.41 & 13.47 \\
\hline \multicolumn{10}{|c|}{ Panel C: Percentage change in specific excise tax compared with previous period } \\
\hline Factory made & & +5.26 & +4.47 & +2.93 & +3.66 & +5.89 & 0.00 & +4.44 & +5.09 \\
\hline Roll your own & & +5.26 & +4.47 & +2.93 & +6.65 & +5.89 & 0.00 & +5.44 & +6.09 \\
\hline \multicolumn{10}{|c|}{ Panel D: Ad valorem and VAT tax rates over time } \\
\hline Ad valorem tax§ (\%) & 16.5 & 16.5 & 16.5 & 16.5 & 16.5 & 16.5 & 16.5 & 16.5 & 16.5 \\
\hline VAT (\%) & 20 & 20 & 20 & 20 & 20 & 20 & 20 & 20 & 20 \\
\hline
\end{tabular}

*Specific tax $\mathrm{f}$ per 1000 cigarettes.

†Minimum excise tax introduced for factory made cigarettes: specific tax plus ad valorem tax (16.5\%) of RRP.

$\ddagger$ Specific tax $\mathrm{f}$ per $1000 \mathrm{~g}$.

$\S$ Applied to FM cigarettes only.

FM, factory made; RRP, recommended retail price; VAT, value-added tax.

which is an ad quantum tax per $1000 \mathrm{FM}$ cigarettes, an ad valorem component which is a percentage of the retail price and the UK value-added sales tax VAT. RYO tobacco has only two components: a specific tax per $1000 \mathrm{~g}$ of RYO tobacco and VAT. During our period of analysis, the ad valorem component for FM cigarettes and VAT remained unchanged, details of the changes in the specific tax and MET are summarised in table 2.

Once we calculated the ad valorem tax for FM cigarettes, we converted all taxes payable for each SKU into per stick and calculated the evolution of expected price per stick for all tobacco products. Following existing literature, as well as best current estimates, we assumed that RYO tobacco is $0.5 \mathrm{~g}$ per stick. ${ }^{13} 1416$ The initial expected price per stick, E[ Price $\left._{i t}\right]$ takes the value of the observed price in the first time period it appears in the data. To construct the evolution of $E$ [Price $\left.{ }_{i t}\right]$ over time, we removed the amount of the specific tax $\left(\right.$ Duty $\left._{i t=1}\right)$ , VAT and ad valorem tax tit $1_{1}$ for FM cigarettes that would have been due at time $t=1$, this leaves only net revenue, see Equation 1 .

Net Revenue $\mathrm{it}_{\mathrm{it}=1}=\frac{\text { Retail Price per Stick } \mathrm{i}_{\mathrm{i}=1}-\text { Specific Duty per Stick } \mathrm{k}_{\mathrm{it}=1}}{\text { VAT } \%_{\mathrm{t}=1}}$

$$
\text { -Ad Valorem Tax per Stick } \mathrm{it}_{\mathrm{t}=1} \text { (B1) }
$$

Net revenue is the money the TI retains from its sales once all taxes and VAT have been paid. This forms a 'baseline' price, which is then inflated to real terms using the Retail Price Index $\left(R P I_{t}\right)$ as this is used to set the path for most specific tax rates in the UK. ${ }^{24}$ RPI is a measure of inflation published monthly by the Office for National Statistics. It measures the change in the cost of a representative sample of retail goods and services. The UK Treasury uses RPI for various index-linked tax rises. This inflated baseline price is then updated over the course of the time frame in the data to reflect the incremental change in specific tax in each following time period. Similarly, if a product's price increases exactly in line with specific tax, VAT and inflation, then its expected price is equal to observed price. Our estimated equation to get expected price becomes as follows:

$E\left[\right.$ Price $\left._{i t}\right]=\left(\left(\right.\right.$ Net Revenue $\left._{\mathrm{it}}\right) \times$ RPI $_{\mathrm{t}}+$ Specific Duty Stick $\left._{\mathrm{it}}\right)$ $\times\left(\mathrm{VAT}_{\mathrm{t}}\right)+$ Ad Valoren Tax per Stick $\mathrm{it}_{\mathrm{it}}(\mathrm{B} 2)$
Panel data quantile regression strategy to estimate tax passthrough across the price range

Similar to evidence examining tax pass-through in the alcohol industry, ${ }^{25}$ we exploit the panel nature of the price data and adopt a quantile regression approach. ${ }^{26}$ Rather than focusing only on the predicted mean of the dependent variable, as in classical linear regression, quantile regression focuses on quantiles which refer to defined points in the price distribution. For example, the 0.50 quantile is the median and 0.05 is the fifth percentile (the cheapest) of the distribution. This allows for the flexibility for modelling the entire distribution of observed prices as the dependent variable. This methodology provides a framework for investigating differential tax pass-through for price points across the entire price distribution.

The basic version of our model is as follows:

$$
\text { Observed Price }_{i t}=\beta_{0}+\beta_{1, \theta} \text { Expected Price }_{i t}+\varepsilon_{i t, \theta}
$$

Where Observed Price ${ }_{i t}$ is the observed price per stick of SKU $i$ at time $t$ in the Nielsen data and Expected Price ${ }_{i t}$ is the price per stick calculated counterfactual price assuming a full tax passthrough. These are both weighted using the volume of sticks sold for each SKU supplied by Nielsen.

Following previous literature in the alcohol market, ${ }^{25}$ we consider 11 quantiles $(0.05,0.15,0.25,0.35,0.45,0.5,0.55$, $0.65,0.75,0.85,0.95$ ) which includes the median $\theta=0.50$ to try and fully capture the price distribution of tobacco. We run the model for FM and RYO separately.

If tax changes are fully passed onto smokers across the price distribution then, for all quantiles, the estimated $\beta_{1}$ coefficient of a given SKU should equal 1. If $\beta_{1}$ is less than 1 , this is an example of undershifting, and the producer is losing some revenue and bears some of the burden of the tax change. If $\beta_{1}$ is great than 1 , this represents overshifting and the smoker is paying more than the $100 \%$ tax pass-through expected price given the tax change, and the TI or retailer is gaining additional revenue.

\section{RESULTS}

\section{Evolution of prices over time}

Figure 1 illustrates the changes in observed price per stick and the calculated counter factual expected price per stick for FM 

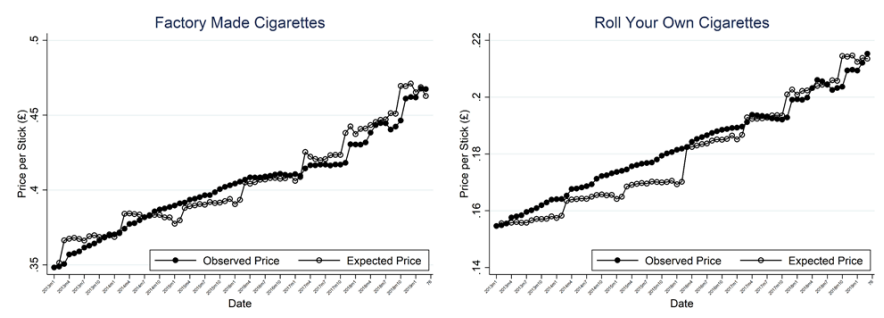

Figure 1 Evolution of prices over time.

and RYO considering the expected impact of both inflation and specific tax changes in subsequent months. We weight these using the market share of the SKU (\% of sticks sold).

In panel A, broadly, FM observed average prices track with expected counterfactual prices, though at times the observed was above and at other times below. This was more prominent when specific tax changes occurred, the observed prices took a few months to catch up. With respect to RYO in panel B, observed prices are above the expected counterfactual prices slightly more often than for FM suggesting that tax pass-through might be slightly higher for RYO than FM.

\section{Descriptive statistics on quantiles of price}

Table 3 summarises the observed price paid per stick for the upper bound of each quantile band $(\theta)$ as well as the percentage sold in each of the 11 quantile bands for FM cigarettes and RYO tobacco. Each $\theta$ quantile can be interpreted as the \% of SKUs in that price band. For example, $\theta \leq 0.05$ equates to $5 \%$ of SKUs in our data set are sold below 33 p per stick. Table 3 illustrates the difference in price between the cheapest products available $(\theta \leq 0.05)$ and the most expensive products $(\theta>0.95)$. This also signifies the large differences in price between FM cigarettes and RYO tobacco, therefore, the quantile bands for FM and RYO are on different scales.

The cheapest RYO (assuming $0.5 \mathrm{~g}$ of tobacco per stick) is 14.2 p per stick, while the cheapest FM stick is 32.9 p. There is also a large difference in price in the most expensive products available. The upper bound for FM is $58.6 \mathrm{p}$, while the most expensive RYO stick is 23.5 p, which is cheaper than the cheapest FM

\begin{tabular}{|c|c|c|c|c|}
\hline & \multicolumn{2}{|c|}{ Factory made cigarettes } & \multicolumn{2}{|c|}{ Roll your own tobacco } \\
\hline & $\begin{array}{l}\text { Price per } \\
\text { stick }(\mathbf{f})^{*}\end{array}$ & $\begin{array}{l}\text { Market share of } \\
\text { sticks sold }(\%) \dagger\end{array}$ & $\begin{array}{l}\text { Price per } \\
\text { stick }(\mathrm{f})^{*}\end{array}$ & $\begin{array}{l}\text { Market share of } \\
\text { sticks sold }(\%) \dagger\end{array}$ \\
\hline $0.95>\theta$ & 0.486 & 9.42 & 0.215 & 22.37 \\
\hline $0.85<\theta \leq 0.95$ & 0.466 & 18.23 & 0.205 & 13.05 \\
\hline $0.75<\theta \leq 0.85$ & 0.424 & 10.70 & 0.194 & 9.94 \\
\hline $0.65<\theta \leq 0.75$ & 0.412 & 16.11 & 0.186 & 13.79 \\
\hline $0.55<\theta \leq 0.65$ & 0.407 & 11.44 & 0.180 & 11.58 \\
\hline $0.50<\theta \leq 0.55$ & 0.392 & 1.65 & 0.174 & 7.99 \\
\hline $0.45<\theta \leq 0.50$ & 0.385 & 2.35 & 0.171 & 7.08 \\
\hline $0.35<\theta \leq 0.45$ & 0.377 & 7.44 & 0.168 & 3.75 \\
\hline $0.25<\theta \leq 0.35$ & 0.365 & 6.77 & 0.163 & 3.83 \\
\hline $0.15<\theta \leq 0.25$ & 0.352 & 6.76 & 0.159 & 3.37 \\
\hline $0.05<\theta \leq 0.15$ & 0.341 & 6.88 & 0.153 & 2.96 \\
\hline$\theta \leq 0.05$ & 0.329 & 2.25 & 0.142 & 0.31 \\
\hline
\end{tabular}

*Price per stick refers to the upper bound of each quantile band $(\theta)$.

tVolume sold is the percentage sold in this category at this price band as a percentage of all FM or RYO sold in this category. Price distribution for a specific product class captures the prices of all products falling within the category. Volume sold refers to the $\%$ sold in each price band, due to rounding, total sales may not sum to $100 \%$.

FM, factory made; RYO, roll your own
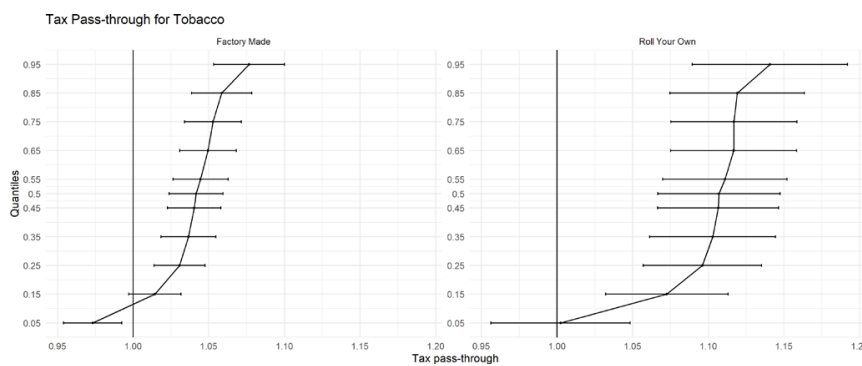

Figure 2 Tax pass-through for tobacco.

cigarettes available. Here we also present the volume of sales for each quantile. For both products, the volume of sales increases the further up the price distribution.

\section{Estimates of pass-through using panel data quantile analysis}

Figure 2 illustrates the tobacco-specific tax pass-through estimates for all FM cigarettes and RYO tobacco (see appendix for regression parameters). At the lowest end of the price distribution $(\theta \leq 0.05)$, our results show that there is undershifting for the cheapest FM cigarettes $0.97(0.95,0.99)$. On the other hand, at $(\theta \leq 0.05)$, the results suggest very close to $100 \%$ tax passthrough for RYO.

On average, the median SKU $(\theta=0.50)$ of FM cigarettes passthrough specific tax changes slightly above the full tax passthrough at $1.04(1.02,1.06)$. However, for RYO this is somewhat higher at $1.10(1.07,1.15)$, suggesting that the TI passes through the change in RYO tax at a higher rate than FM.

For the remaining quantiles, there is evidence to suggest clear overshifting of tax on to smokers, that is, prices are going up more than the specified tax increase. The interesting narrative however is that the overshift is smallest at the lower end of the price distribution. At $\theta=0.25$, the rate of tax pass-through is $1.03(1.01,1.04)$ for FM and $1.10(1.06,1.13)$ for RYO, while at the higher end of the price distribution $(\theta=0.75)$ this increases to $1.05(1.03,1.07)$ and $1.12(1.08,1.16)$ for FM and RYO, respectively.

These estimates show that while the TI is increasing the prices of their products beyond that of the tax increase, they are still trying to keep the cheapest products cheap relative to the more 'premium' and more expensive products. This outcome is consistent for both FM and RYO tobacco. As a result, this widens the gap between the cheapest and more expensive products as prices have increased at a greater rate at the higher end of the price distribution.

\section{Standardised packaging}

Our period of analysis covers both prestandardised and poststandardised packaging and the introduction of the MET. In figure 3, we split our sample into 'branded packaging' which is the old-style, colourful packaging which was sold in a variety of stick sizes and the new style 'standardised packaging'. We estimate separately the tax pass-through of the specific tax increases prestandardised and poststandardised packaging. We find that the rates of tax pass-through for FM and RYO do not vary across the introduction of standardised packaging. There is marginally lower tax pass-through after standardised packaging compared with before, for example, $1.04(1.02,1.06)$ compared with 1.02 $(1.01,1.05)$ at $\theta=0.50$ for FM product, however, they are not statistically different to each other. This pattern is consistent in the two periods. 


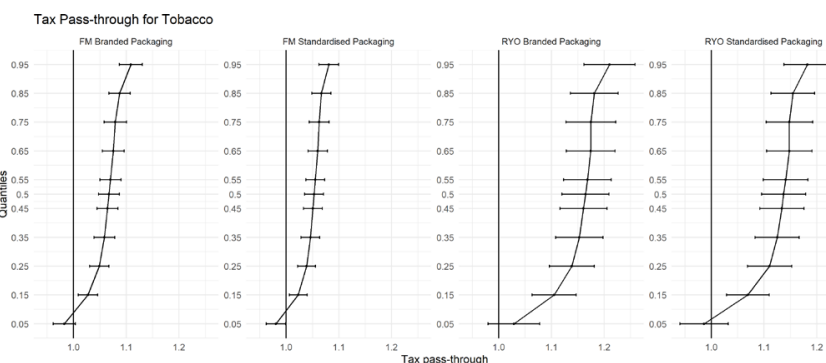

Figure 3 Tax pass-through for tobacco prestandardised and poststandardised packaging. FM, factory made; RYO, roll your own.

\section{DISCUSSION}

This paper uses quantile regression for panel data to estimate the rate of tax pass-through in the market for tobacco. We find that the TI predominantly overshifts tax in the form of higher than expected prices. Furthermore, we find that the magnitude of the overshift is greater at the more expensive end of the price distribution, relative to the cheaper products available. This is consistent for both FM and RYO.

Research conducted prestandardised packaging in the UK found that the TI uses a variety of strategies to keep the cheapest FM cigarettes and RYO tobacco cheap. ${ }^{13} 141618$ We find that our results are consistent with the previous literature as the rate of the overshift is greater the higher up the price distribution.

One of the main arguments the TI made in its opposition to the introduction of standardised packaging was that it would result in the commoditisation of tobacco and reduce prices. Previous evidence showed the introduction of standardised packaging did not lead to a long-term decline in cigarette prices. ${ }^{15}$ We also show that the rates of tax pass-through for branded versus standardised packaging do not differ significantly since the implementation of standardised packaging and have a longer follow-up period.

Another strength of our analysis is our use of quantile regression for panel data to estimate the rate of tax pass-through in the market for tobacco. Unlike previous analyses which used a price segmentation approach via a commercial literature review, we were able to break the market into consistent, exogeneously defined, quantiles. That both approaches revealed similar findings provides triangulation.

While we provide new evidence regarding the extent of tax pass-through by the TI, our work is not without limitations. Due to commercial sensitivity, we are unable to obtain the exact ad valorem rate payable or RRP suggested by the TI for each SKU in the Nielsen data. Instead, we use similar methods from the previous literature ${ }^{13-15}$ as well as conversations with Her Majesty's Revenue and Customs to calculate the ad valorem tax for each SKU. Following this guidance, we are confident that our estimates are close to those paid.

There is some further potential thinking to be done about how these findings are related to understanding of price elasticities for tobacco. Most of the current estimates on price elasticity estimates for tobacco examine average mean changes in sales or purchasing and there is little published evidence on differential price elasticities at different price points across the price distribution or across product segments. Our research illustrates that the TI passes on tax increases heterogeneously across the price distribution; an extension to this can be to examine how smokers respond to the price increases they face.
What this paper adds

- Previous work in the UK has shown that the tobacco industry (TI) passed tax duty increases on to smokers at different magnitudes depending on the market segment of the product.

- The TI did this by absorbing tax increases on the defined 'subvalue' and 'value' products, while simultaneously increasing the price, above the tax increase, of the relatively more 'premium' products in order to maximise revenue.

- What is not as clear is how the rate of tax pass-through, following specific tax increases, varies across the price distribution of factory made cigarettes and roll your own tobacco as tobacco product segmentation overlaps across the price distribution.

- We create a counterfactual expected price taking into consideration specific tax increases and inflation in the UK and undertake quantile regression of this against market research pricing data to estimate tax pass-through of factory made cigarettes and roll your own tobacco across the price distribution of prices faced by smokers.

- The statistical analysis in this paper extends previous work by applying panel data quantile regression methods to the monthly pricing data in order to produce estimates of undershifting or overshifting of tobacco tax changes at various price points across the entire distribution, covering the cheapest to most expensive products available to smokers.

- Our evidence shows that the TI overshifts tax increases at a higher rate for the more expensive products relative to the cheapest products at the lower end of the price distribution. This is consistent for both factory made and roll your own tobacco.

\section{CONCLUSIONS}

Our results show that tax increases introduced in the UK lead to increases in the price of tobacco paid by smokers across the price distribution and therefore support the extensive evidence on the effectiveness of duty increases on reducing tobacco consumption and prevalence. However, our results also indicate that the TI keeps the cheaper tobacco products cheaper than the more 'premium' products by overshifting taxes at a lower rate.

Twitter Colin Angus @VictimOfMaths

Acknowledgements Thank you to seminar participants at Health Economics at Lancaster (HEAL), Lancaster University.

Contributors All authors contributed to the analysis plan. RH was responsible for data access and initial data cleaning. Statistical analysis was conducted by LBW and RP. LBW drafted the paper. All authors provided comments and revisions to the manuscript.

Funding This research was funded by the NIHR Public Health Research programme (Project Ref 16/105/26). The views expressed are those of the author(s) and not necessarily those of the NHS, the NIHR or the Department of Health and Social Care.

Competing interests CA has received funding related to commissioned research from Systembolaget and Alko, the Swedish and Finnish government-owned alcohol retail monopolies.

\section{Patient consent for publication Not required.}

Provenance and peer review Not commissioned; externally peer reviewed.

Data availability statement Data may be obtained from a third party and are not publicly available. We do not have the right to share the Nielsen data. Researchers must contact Nielsen directly to purchase a copy of the data. We are able to make the instructions and code available by posting detailed documentation 
on our code and programs, instructions on how researchers can obtain the data, and online readme files.

Open access This is an open access article distributed in accordance with the Creative Commons Attribution 4.0 Unported (CC BY 4.0) license, which permits others to copy, redistribute, remix, transform and build upon this work for any purpose, provided the original work is properly cited, a link to the licence is given, and indication of whether changes were made. See: https://creativecommons.org/ licenses/by/4.0/.

\section{ORCID iDs}

Luke Brian Wilson http://orcid.org/0000-0001-5769-5729

Rosemary Hiscock http://orcid.org/0000-0001-9741-9083

\section{REFERENCES}

1 Farley SM, Coady MH, Mandel-Ricci J, et al. Public opinions on Tax and retail-based tobacco control strategies. Tob Control 2015;24:e10-13.

2 Levy DT, Ellis JA, Mays D, et al. Smoking-Related deaths averted due to three years of policy progress. Bull World Health Organ 2013;91:509-18.

3 Nagelhout GE, Levy DT, Blackman K, et al. The effect of tobacco control policies on smoking prevalence and smoking-attributable deaths. findings from the Netherlands SimSmoke tobacco control policy simulation model. Addiction 2012;107:407-16.

4 Wakefield MA, Durkin S, Spittal MJ, et al. Impact of tobacco control policies and mass media campaigns on monthly adult smoking prevalence. Am J Public Health 2008:98:1443-50.

5 Wilson LM, Avila Tang E, Chander G, et al. Impact of tobacco control interventions on smoking initiation, cessation, and prevalence: a systematic review. J Environ Public Health 2012;2012:1-36.

6 Azagba S, Sharaf M. Cigarette taxes and smoking participation: evidence from recent Tax increases in Canada. Int J Environ Res Public Health 2011;8:1583-600.

7 Carpenter C, Cook PJ. Cigarette taxes and youth smoking: new evidence from national, state, and local youth risk behavior surveys. J Health Econ 2008;27:287-99.

8 DeCicca P, Kenkel D, Liu F. Excise tax avoidance: the case of state cigarette taxes. J Health Econ 2013;32:1130-41.

9 Gallego JM, Otálvaro-Ramírez S, Rodriguez-Lesmes PA. Price smoking participation elasticity in Colombia: estimates by age and socioeconomic level. Tob Control 2020. doi:10.1136/tobaccocontrol-2019-055186. [Epub ahead of print: 11 Feb 2020].
10 Kostova D, Chaloupka FJ, Shang C. A duration analysis of the role of cigarette prices on smoking initiation and cessation in developing countries. Eur J Health Econ 2015;16:279-88.

11 Lillard DR, Molloy E, Sfekas A. Smoking initiation and the iron law of demand. J Health Econ 2013;32:114-27.

12 Zhang B, Cohen J, Ferrence R, et al. The impact of tobacco Tax cuts on smoking initiation among Canadian young adults. Am J Prev Med 2006;30:474-9.

13 Hiscock R, Branston JR, McNeill A, et al. Tobacco industry strategies undermine government Tax policy: evidence from commercial data. Tob Control 2018;27:488-97.

14 Hiscock R, Branston JR, Partos TR, et al. Uk tobacco price increases: driven by industry or public health? Tob Control 2019;28:e148-50.

15 Hiscock R, Augustin NH, Branston JR, et al. Standardised packaging, minimum excise tax, and RYO focussed Tax rise implications for UK tobacco pricing. PLoS One 2020;15:e0228069.

16 Gilmore AB, Tavakoly B, Taylor G, et al. Understanding tobacco industry pricing strategy and whether it undermines tobacco Tax policy: the example of the UK cigarette market. Addiction 2013;108:1317-26.

17 Gilmore AB, Reed H. The truth about cigarette price increases in Britain. Tob Control 2014;23:e15-16.

18 Hiscock R, Augustin NH, Branston JR, et al. Longitudinal evaluation of the impact of standardised packaging and minimum excise tax on tobacco sales and industry revenue in the UK. Tob Control 2020. doi:10.1136/tobaccocontrol-2019-055387. [Epub ahead of print: 12 Jul 2020].

19 Opazo Breton M, Britton J, Bogdanovica I. Changes in roll-your-own tobacco and cigarette sales volume and prices before, during and after plain packaging legislation in the UK. Tob Control 2020;29:263-8.

20 Nielsen. Retail measurement service design summary, 2017.

21 Greenland SJ. The Australian experience following plain packaging: the impact on tobacco branding. Addiction 2016;111:2248-58.

22 Lane Keller K. Designing and implementing brand architecture strategies. J Brand Manag 2014;21:702-15.

23 Dewhirst T. Into the black: Marlboro brand architecture, packaging and marketing communication of relative harm. Tob Control 2018;27:240-2.

24 HM Treasury. Autumn budget, 2018.

25 Ally AK, Meng Y, Chakraborty R, et al. Alcohol Tax pass-through across the product and price range: do retailers treat cheap alcohol differently? Addiction 2014;109:1994-2002.

26 Koenker R. Quantile regression for longitudinal data. J Multivar Anal 2004;91:74-89. 